\title{
The Shells
}

\section{Seepyan*}

Translated by Hari Priya Pathak

I was trailing my shadow. I knew that the sunlight sporting with the sea waves will keep following me. It will never come before me. The sea was afar. My feet began to sink into the sand when I went forward with the dream to catch the smile of the sun beams floating on the sea surface.

I collected small shells scattered on the sand before returning, and kept deceiving the disappointment of my failure to catch the sun light floating on the sea waves by considering those broken shells my achievement.

I would run towards the sea whenever I had a desire to catch the sun light. I would collect the shells to make up for the failure of catching the glistening sea waves. Consequently, my house was heaped with various kinds of shells-small and big, broken and whole, striped and plain with beautiful colors.

What could I do with them? I could not think of anything. Shells were all around. There wasn't even sitting and sleeping space left for me. The guests were to arrive. I had to clean the house, but I could not throw out the shells which I had amassed with great enthusiasm. I was attached with each of the shells. Each one of them had an anecdote linked to it. Each broken shell would tell the story of its own living form sticking to which and listening to the music of the waves it had attained its youth, and one day was separated from that living being and thrown to the sea shore by the sea waves. It was because of these shells that I never felt lonely at my house. Whenever I would be alone, my eyes would fix on to one of those shells, which then would start narrating its own tale. I just could not 
do away with them, and that is why my house remained unkempt.

"What's all this?" They asked as soon as they reached

“This is my earning; earning of my life." I said

"This? This is your earning? You always used to go on the trip to sea side places. Was this the only thing there? We used to think that you would have decorated your house with several pearls by this time."

Wouldn't they be found only by diving deep into the sea? I had visited only the sea shores.

"But what to do of this apparently useless heap?"

"You can make beautiful things out of it and can decorate the house. You can put them together and gift them to the people."

"How? It's already evening. The time is coming to a close. How would it all be possible so soon?"

"There's a lot of time between evening and night, begin with it. Put together all the shells making each moment the thread."

They went outside saying this. My house had heaps of broken shells. I threaded them all through the evening. My hands were bruised, eyes swelled up, but I kept threading, decorating them. Earlier it was my feet which tired, now my hands were exhausted, my eyes weary. People moving in and out would continuously evaluate me and criticize me from their own points of view. They all wanted me to make beautiful garlands and 'torans' for them, but what was actually beautiful couldn't be made out. Some considered long garlands to be beautiful, others short ones. Some would say, "It doesn't have a proper shape." Others would comment, "The color combination is not good." Some wanted some other things than garlands. Some asked for toran and others bandanwaar. Some wanted to 
entrap the newspaper in the net made up of the shells, while others wanted to have made a case for keeping the letters safely; still others wanted to see the shells in the form of a bouquet. I had only two hands. They had hundreds of tongues, thousands of eyes and millions of expectations. How and for how long could I satisfy all of them?

I didn't have a single pearl at my house.

I had all the garbage of the shells at my house.

I received the gifts of criticism.

I adorned the walls of my house with them; made carpets out of the shells and spread them on the floor.

The whole house was decorated, and then the night broke out. I jumped into the river of darkness.

The carpet had become the waves of the sea. It was echoing the sea...

I was going into the water, down and down....deep and deeper........

\section{Note}

Toran and Bandhanwaar are garlands made up of flowers, real or artificial, or shells or any other thing to embellish gates, doors, main pathways or walls in a house.

* The above translation of the short story "Seepyan" written in Hindi by Diwa Bhatt has been originally published in Aakar15, Jan-Feb-Mar, 2004, Ahmedabad (Gujrat) 